\title{
Modifikasi Mesin Produksi di UKM sebagai Implementasi dari Ecodesign
}

\author{
Sulistiarini Emma B, Wardhani Arie R. \\ Jurusan Teknik Industri Fakultas Teknik \\ Universitas Widya Gama Malang
}

\begin{abstract}
ABSTRAK
Penelitian ini melakukan modifikasi terhadap mesin produksi pencetakan kerupuk sebagai penerapan prinsip ecodesign, yaitu menghasilkan desain yang menghasilkan penurunan waste dan penurunan biaya. Yang lebih urgent lagi adalah kenyamanan kerja bagi manusia/operator sehingga tidak menimbulkan kelelahan, kecelakaan kerja, penyakit dalam jangka panjang ke depan. Dari hasil modifikasi didapatkan penurunan waste dari $2,5 \%$ per $100 \mathrm{~kg}$ bahan menjadi $0,2 \%$ per $100 \mathrm{~kg}$. Dan mengurangi biaya Rp. 20.000/ hari untuk biaya tenaga kerja. Kenaikan produktivitas dari penelitian ini didapatkan $80 \%$.
\end{abstract}

Kata kunci : ecodesign, waste, penurunan biaya, kenyamanan kerja.

\section{PENDAHULUAN}

Sekitar kurang lebih 50 Usaha Kecil Menengah di bidang Kerupuk banyak tumbuh di kota Malang, hal ini wajar karena kerupuk memang makanan pendamping nasi seharihari bagi sebagian besar masyarakat Indonesia. Inovasi terhadap Usaha Kecil Menengah perlu diupayakan terus-menerus, karena Usaha Kecil Menengah merupakan tulang punggung ekonomi Indonesia. UKM di Indonesia sangat keberlanjutannya, karena menyumbang $60 \%$ dari PDB dan menampung $97 \%$ tenaga kerja. Disamping itu, APO sendiri memberikan perhatian khusus pada UKM sebagai bentuk pengakuan tentang peran penting UKM dalam pengembangan ekonomi, terjadinya degradasi lingkungan, kurangnya sumberdaya dan keahlian, hal yang umumnya dapat menghambat kemajuan UKM (Tuttle Tom, Heap John, 2007). Dalam UKM Kerupuk yang berada di Blimbing Malang ini, adonan yang sudah diberi bumbu dimasukkan ke dalam tabung pencetak berdaya tampung \pm $20 \mathrm{~kg}$ kemudian ditekan dengan cara memutar roda gigi mekanis yang berat dengan menggunakan tenaga manusia. Pemutaran roda gigi mekanis dilakukan dengan cara menarik tuas roda gigi yang telah diberi tali, kemudian tali tersebut diikat pada dada dan punggung pekerja untuk selanjutnya pekerja tersebut bergerak memutar dengan beban yang berat. Putaran roda gigi diperlukan untuk menekan adonan dalam tabung agar mampu melewati nozzle pencetak kerupuk. Beberapa pedoman umum dalam melakukan ecodesign (Fiksel dalam Miriam at all, 2011) diantaranya adalah memilih dan menggunakan material tertentu, terutama yang dapat mempengaruhi lingkungan, termasuk kemampuan daur ulang dan penggunaan kembali, pemilihan komponen produk yang dapat melihat kemampuan perbaikan kembali, karakteristik produk yang dapat mengurangi pemakaian material, penggunaan energi terbarukan, pengurangan pemakaian energi pada saat penggunaan produk, pada saat produksi dan pada saat penyimpanan. Bahkan ecodesign juga memperhatikan sejauh mana distribusi dapat meminimalkan stok dan jalur distribusi, meminimalkan berat packaging, meminimalkan produksi waste dan sebagainya. Dari observasi pendahuluan dijumpai bahwa kelemahan proses pencetakan adalah pekerja menjadi lebih cepat lelah akibatnya sering berhenti untuk beristirahat, sehingga dampaknya selain produktivitas rendah juga menyebabkan adonan cepat kering dan menyumbat nozzle pencetak kerupuk dan pada akhirnya nozzle harus sering dibersihkan dari sumbatan dengan membuang sebagian adonan yang agak mengering. Dalam setiap satu sesi proses pencetakan terdapat adonan yang mengering dan harus dibuang berkisar antara $0.5 \mathrm{~kg}$ per sesi, maka jika dalam sehari terdapat lima kali sesi pencetakan, adonan yang berpotensi dibuang berkisar antara $2.5 \mathrm{~kg}$. Hal ini merupakan pemborosan bahan baku dan material yang pada dasarnya bahan baku dan material kerupuk tersebut juga didapatkan dari alam (tepung). 


\section{PERMASALAHAN}

Bagaimana melakukan modifikasi terhadap mesin produksi pencetakan, agar memenuhi beberapa kriteria ecodesign? Tujuan penelitian ini adalah memperbaiki proses produksi khususnya proses pencetakan pada UKM kerupuk melalui modifikasi mesin agar lebih mudah dan lebih nyaman dalam pengoperasiannya, efisiensi material dan waste, pengurangan biaya produksi lainnya serta dapat meningkatkan produktivitas. Adapun manfaat penelitian yang diperoleh adalah dapat memberi kontribusi dan wawasan terhadap keberlanjutan hidup UKM, dengan modifikasi mesin produksi ecodesign yang diaplikasikan langsung pada Usaha Kecil Menengah di bidang kerupuk.

\section{METODE PENELITIAN}

Dalam riset ini, dipelajari dulu keseluruhan proses produksi kerupuk dari mulai raw material sampai dengan produk jadi dan penyimpanan. Dari point ini, dijumpai beberapa proses yang tidak memenuhi prinsip ecodesign, seperti pada proses pencetakan kerupuk sebagaimana yang dijelaskan sebelumnya, juga pada proses penggorengan dan proses steam. Output dari observasi proses produksi adalah peta proses operasi yang dapat dilihat pada gambar 1 . Selanjutnya dipilih salah satu proses yang mendesak untuk diperbaiki, yaitu pada proses pencetakan kerupuk dikarenakan menggunakan tenaga manusia (dalam hal ini perempuan) dalam memutar mesin sepanjang prosesnya. Sedangkan proses penggorengan kerupuk yang masih memakai bahan bakar kayu diagendakan untuk penelitian selanjutnya. Proses modifikasi mesin pencetakan dilakukan dan dianalisis ecodesign, yang mana selain memberikan ekoefisiensi juga ekoefektif atau dapat meningkatkan produktivitas.

\section{HASIL DAN PEMBAHASAN}

Peta proses operasi pada Usaha Kecil Menengah kerupuk diperlihatkan pada gambar 1 dengan tahapan sebagai berikut :

- Pada langkah awal, tepung $20 \mathrm{~kg}$ dicampur air, diberi bumbu, lalu diaduk secara manual sampai terasa liat, proses ini diperiksa agar kekenyalannya bisa terbentuk. Tidak ada indikator untuk mengukur kekenyalan, diperlukan pengalaman untuk memeriksanya.

- Setelah adonan siap, langsung dan segera dimasukkan ke dalam tabung pencetakan kerupuk. Untuk membawa adonan ini ke tabung, pekerja menaiki tangga dengan beban yang cukup berat. Setelah siap semua, mesin pencetak kerupuk dijalankan secara manual. Pekerja memutari mesin agar tabung bergerak menekan adonan. Caranya tali dikaitkan pada pinggang pekerja, dan pekerja berjalan memutari mesin dengan jarak putar/diameter sekitar 5 meter.

- Adonan kerupuk mengalir lewat nozzle, ditampung di cetakan sehingga terbentuk bulatan-bulatan sedang. Lubang nozzle yang dialiri adonan berjumlah dua buah. Bulatan kerupuk atau produk setengah jadi tersebut kemudian diangin-anginkan.

- Setelah terdapat beberapa nampan bambu, produk setengah jadi disteam. Proses ini menggunakan bahan bakar dari kayu, yang menimbulkan asap dan jelaga.

- Penggorengan dilakukan setelah kerupuk dijemur di sinar matahari. Penggorengan memakai kayu bakar.

- Pemeriksaan dilakukan untuk memilih kerupuk yang tidak utuh (gempil), terlalu gosong, kotor, lalu dipacking dalam plastik karung.

- Karung-karung plastik disimpan, siap didistribusikan oleh para pedagang. 


\section{OPERATION PROCESS CHART \\ PENGOLAHAN KRUPUK}

Charted By PDP

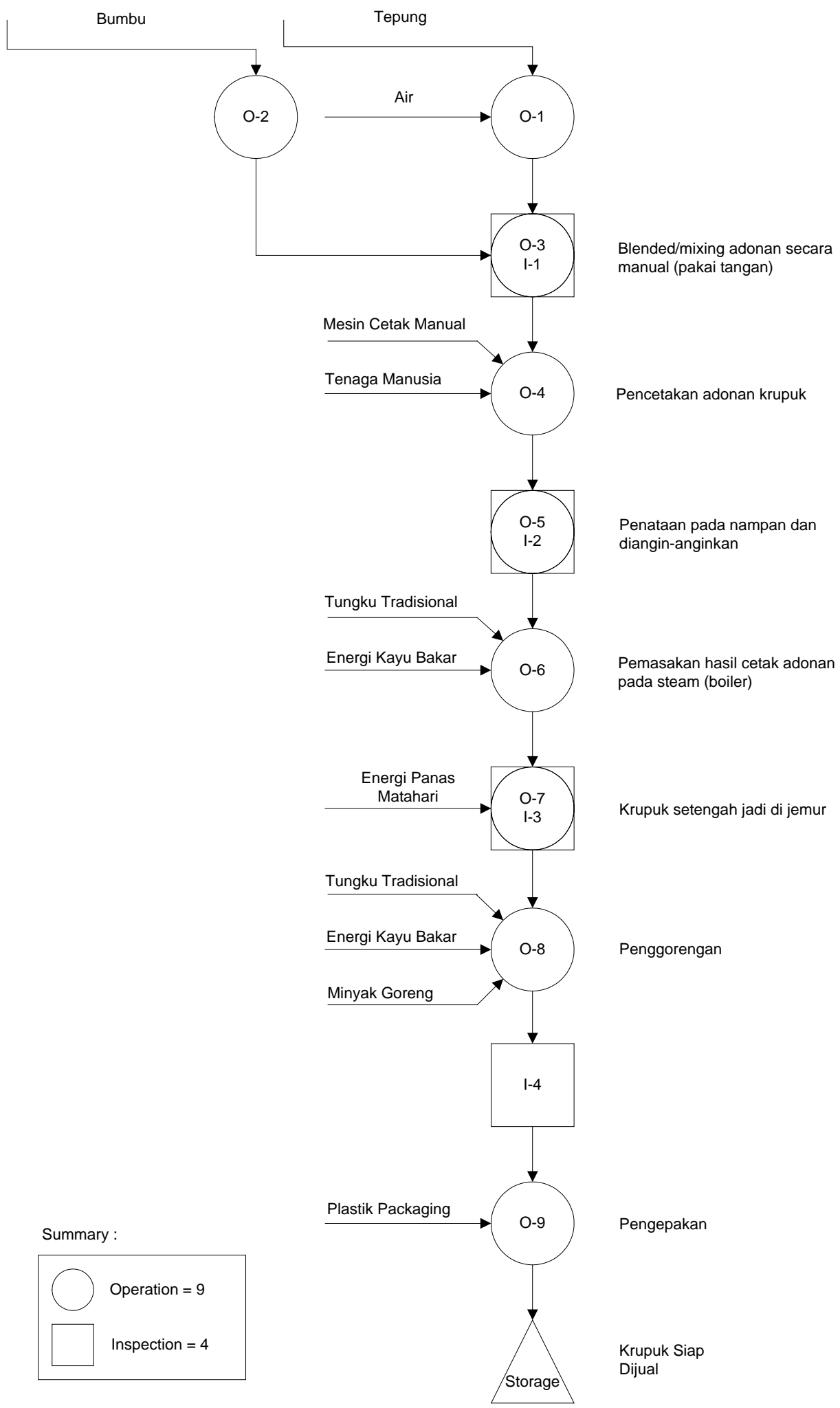

Gambar 1. OPC Pengolahan Kerupuk 
Dari gambar 1 tersebut, diperoleh beberapa proses yang tidak ecodesign yaitu :

1. Proses cetak

Proses cetak adalah salah satu proses pembuatan kerupuk, dimana adonan tepung dicetak menjadi bentuk bulat-bulat sedang. Pada proses ini, mesin yang digunakan manual, dan energi penggeraknya adalah manusia. Pada proses cetak manual ini juga didapatkan waste material adonan tepung, sebagai akibat dari ketidaksempurnaan proses pencetakan dengan tenaga manusia.

2. Proses steam

Proses steam adalah bagian dari proses pembuatan kerupuk, dimana kerupuk setengah jadi dimasak dengan melalui tungku tradisional dengan menggunakan bahan bakar kayu sisa dari bangunan. Prinsip proses steam ini adalah proses pemasakan hasil cetakan adonan kerupuk dengan memanfaatkan uap panas yang dihasilkan dari proses pembakaran kayu dalam tungku tradisional yang dialirkan melalui pipa, kemudian uap panas tersebut ditampung dalam bejana tertutup yang didalamnya sudah diletakkan hasil cetakan adonan kerupuk dengan waktu tertentu sampai dengan matang.

3. Proses penggorengan

Sebagaimana proses steam, dalam proses penggorengan ini juga menggunakan tungku tradisional dengan bahan bakar kayu. Kerupuk digoreng dalam wajan besar dengan media minyak goreng.

Dalam penelitian ini membatasi pada proses cetak, karena beberapa pertimbangan krusial berikut ini:

- mesin manual memakai energi penggerak dari manusia

- prosesnya tidak efisien dan tidak efektif

- mempunyai waste

Lingkup permasalahan pada proses cetak dapat juga dilihat dari material balance berikut ini:

\section{MATERIAL BALANCE}

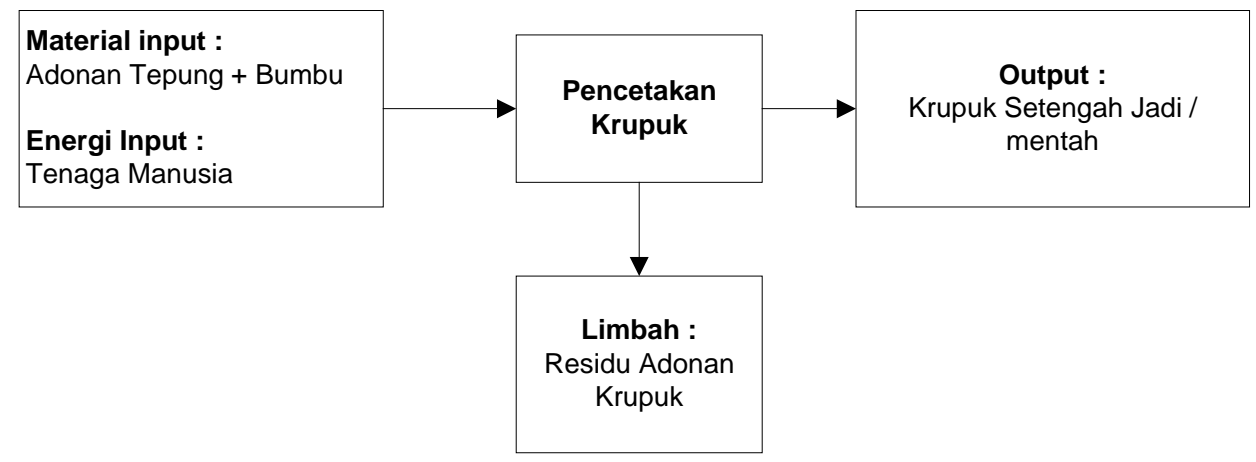

Gambar 2. Timbulnya Limbah dari Desain Sebelumnya

\section{Modifikasi Mesin Produksi}

Fokus perancangan dan rekayasa desain mesin pencetak ini adalah perubahan pada sistem penggerak manual dan mekanis menjadi berpenggerak elektris dengan menggunakan motor listrik. Secara teknis, putaran roda gigi penekan yang dibutuhkan adalah putaran rendah atau low speed/rpm, oleh karenanya selain motor listrik putaran rendah juga diperlukan sebuah inverter motor guna kemudahan pengaturan kecepatan putaran motor tinggi/rendah. Pembuatan kerangka mesin juga diperlukan sebagai penyangga motor listrik serta penguat konstruksi mesin secara umum. 


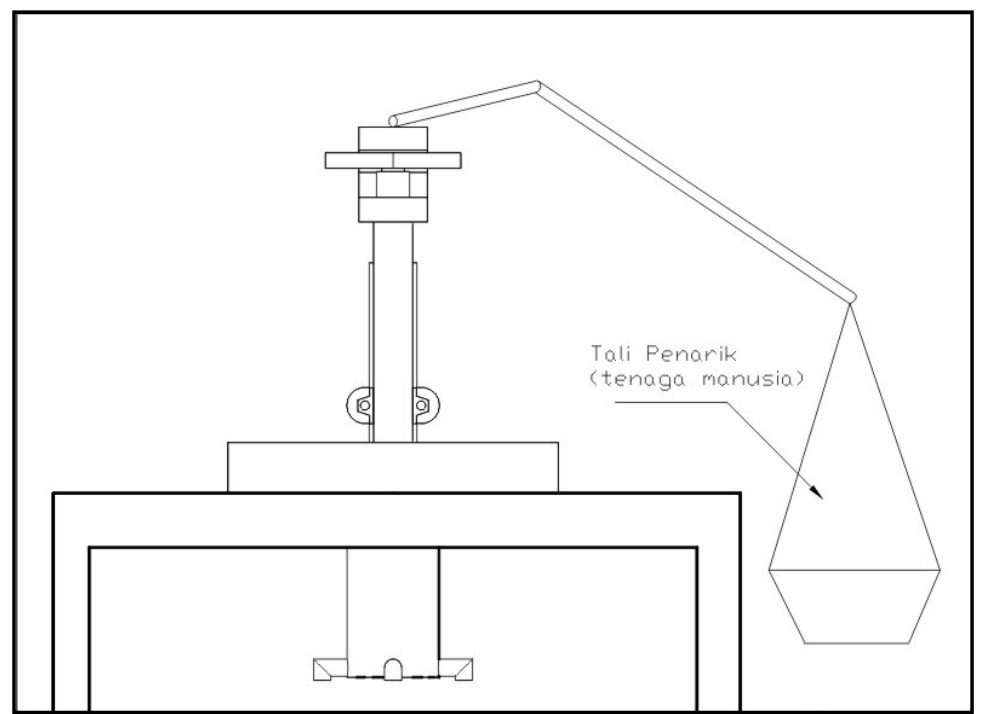

Gambar 3. Mesin Pencetak Kerupuk yang Tidak Memenuhi Prinsip Ecodesign

Spesifikasi dari perancangan mesin yang baru adalah sebagai berikut :

- Motor listrik $1 \frac{1}{2}$ PK, 220V, 360 Watt

- Inverter 1 phase / 3 phase 220V

- Automatic limit switch / auto off

- Kerangka mesin dari plat besi dan besi UNP

- Diameter hopper $20 \mathrm{~cm}$, kedalaman $50 \mathrm{~cm}$

- $\quad$ Kapasitas hopper $=20 \mathrm{~kg}$ adonan

Adapun gambar Mesin Pencetak Kerupuk Mekanis yang memenuhi Prinsip Ecodesign hasil rancangan sebagai berikut :

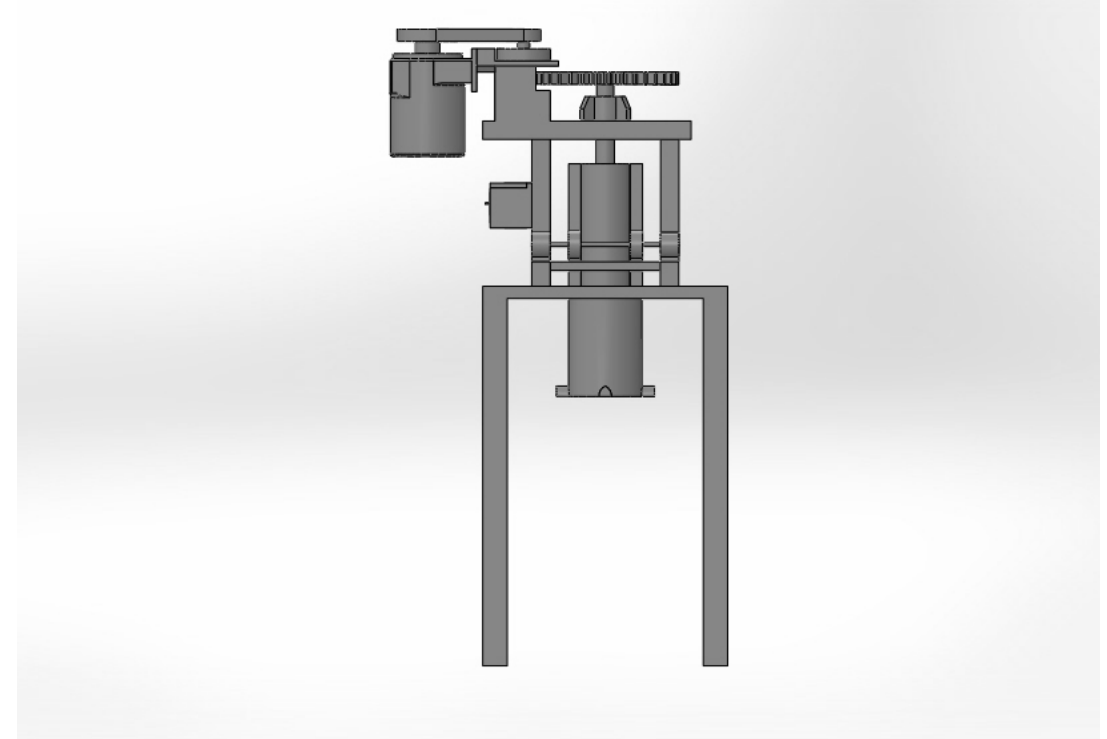

Gambar 4. Mesin Pencetak Kerupuk Hasil Modifikasi

Mesin baru ini menggunakan motor listrik $1 / 2$ PK sebagai penggerak utama dengan pengatur kecepatan (speed) menggunakan teknologi inverter, sehingga pengoperasian (kecepatan putaran) mesin dapat di atur sesuai dengan kebutuhan operator. Putaran mesin yang digerakkan oleh motor listrik mengeleminasi kebutuhan operator (manusia/ tenaga kerja), 
sehingga tenaga kerja dapat dioptimalkan pada stasiun kerja lain. Guna mengontrol putaran mesin ketika adonan telah habis, maka pada mesin tersebut diberikan limit switch auto off, sehingga mesin akan secara otomatis berhenti ketika adonan dalam tabung telah habis.

\section{Analisis}

Hal-hal yang membedakan dalam penggunaan mesin lama dengan mesin baru adalah sebagai berikut :

Tabel 1. Perbedaan antara Mesin Lama dan Mesin Baru

\begin{tabular}{|c|c|c|c|}
\hline & \multirow{2}{*}{$\begin{array}{l}\text { Mesin Awal } \\
\text { Keterangan }\end{array}$} & \multicolumn{2}{|c|}{ Mesin Baru } \\
\hline Hal & & Hal & Keterangan \\
\hline Biaya tinggi & $\begin{array}{l}\text { Tenaga kerja } \quad \text { yang } \\
\text { mengoperasikan } 3 \text { orang, } \\
\text { silih berganti per } 15 \text { menit, } \\
\text { dengan biaya Rp. } 20.000 \times 3 \\
\text { orang = Rp. } 60.000 / \text { hari. }\end{array}$ & Cost Reduction & $\begin{array}{l}\text { Dapat dikerjakan hanya } \\
\text { dengan } 2 \text { orang tenaga } \\
\text { kerja, biaya menjadi Rp. } \\
20.000 \times 2 \text { orang = Rp. } \\
40.000 / \text { hari. }\end{array}$ \\
\hline $\begin{array}{l}\text { Produktivitas/ } \\
\text { Kapasitas } \\
\text { Produksi }\end{array}$ & $\begin{array}{l}\text { Kapasitas produksi max }=5 \\
\text { cycle x } 20 \mathrm{~kg}=100 \mathrm{~kg} \text { per } \\
\text { hari }\end{array}$ & $\begin{array}{l}\text { Increase } \\
\text { Productivity/ } \\
\text { Capacity }\end{array}$ & 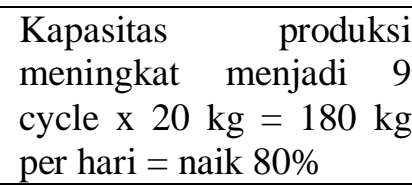 \\
\hline $\begin{array}{l}\text { Production } \\
\text { Output }\end{array}$ & $\begin{array}{l}5 \times 2.730=13.650 \text { kerupuk } \\
\text { per hari }\end{array}$ & $\begin{array}{l}\text { Increase } \\
\text { Production } \\
\text { Output }\end{array}$ & $\begin{array}{l}9 \times 2.800=25.200 \\
\text { kerupuk per hari }\end{array}$ \\
\hline Waste & $2.5 \%$ per $100 \mathrm{~kg}$. & Minimize waste & $+/-0,2 \%$ \\
\hline Raw material & $\begin{array}{l}\text { Material input }=100 \mathrm{~kg} \\
\text { Output }=97,5 \mathrm{~kg} \text {, efisiensi : } \\
97,5 \% \text { Atau } \\
1 \mathrm{~kg} \text { bahan }=136 \text { buah } \\
\text { kerupuk }\end{array}$ & Reduce Material & $\begin{array}{l}\text { Input } 100 \mathrm{~kg}, \text { Output = } \\
99,8 \mathrm{~kg} \text {, efisiensi : 99,8\% } \\
\text { Atau } \\
1 \mathrm{~kg} \text { bahan = } 140 \text { buah } \\
\text { kerupuk }\end{array}$ \\
\hline Energy & Human force & Energy & Listrik \\
\hline
\end{tabular}

Perancangan mesin produksi ecodesign di UKM kerupuk adalah seperti dalam tabel berikut :

Tabel 2. Aplikasi Ecodesign pada Modifikasi Mesin Pencetak Kerupuk

\begin{tabular}{|l|l|}
\hline \multicolumn{1}{|c|}{$\begin{array}{c}\text { Modifikasi Mesin dalam rangka } \\
\text { Implementasi Ecodesign }\end{array}$} & \multicolumn{1}{|c|}{ Action } \\
\hline Penggunaan energi & $\begin{array}{l}\text { Meningkatkan human life dengan mengganti } \\
\text { human power dengan mesin listrik berdaya } \\
\text { rendah +/- 360 Watt. }\end{array}$ \\
\hline Pengurangan waste & $\begin{array}{l}\text { Lebih ramah lingkungan dengan adanya } \\
\text { pengurangan waste yang semula 2,5\% menjadi } \\
\text { hanya 0,2\%. Waste yang terjadi disebabkan } \\
\text { oleh tenaga penggerak manusia yang tidak } \\
\text { konstan kecepatannya, sehingga menyebabkan } \\
\text { raw material kering menyumbat nozzle dan } \\
\text { harus dibersihkan, dan kultur masyarakat } \\
\text { tradisional membuangnya langsung pada } \\
\text { lingkungan sekitar }\end{array}$ \\
\hline Kapasitas produksi & $\begin{array}{l}\text { Kapasitas produksi meningkat secara } \\
\text { signifikan yaitu dari kapasitas awal sebesar }\end{array}$ \\
& $\begin{array}{l}\text { 100 kg per hari menjadi 180 kg per hari atau } \\
\text { naik sebesar 80\%. Hal ini dapat terjadi karena } \\
\text { mesin yang semula sangat tergantung dengan }\end{array}$ \\
\hline
\end{tabular}




\begin{tabular}{|l|l|}
\hline & $\begin{array}{l}\text { kondisi operator (faktor kelelahan) untuk } \\
\text { memutar dapat digantikan oleh motor } \\
\text { penggerak dengan memanfaatkan energi }\end{array}$ \\
listrik, sehingga faktor kelelahan operator \\
dapat dieliminasi.
\end{tabular}

Perhitungan ecoefisiensi dari segi biaya yang dikeluarkan adalah berikut ini :

Tabel 3. Perhitungan Return of Investment dari Mesin

\begin{tabular}{|l|l|}
\hline \multicolumn{1}{|c|}{ Investasi } & \multicolumn{1}{c|}{ Value } \\
\hline Biaya perancangan mesin & Rp. 5.000.000,- \\
\hline Jumlah mesin yang diperlukan & 1 \\
\hline Total investasi ( a 1) & Rp. 5.000.000,- \\
\hline Economic gains & Value \\
\hline \multicolumn{1}{|c|}{ Pengurangan biaya perhari } & Rp. 20.000,- per hari (reduce labour cost) \\
\hline Peningkatan pendapatan & $25.200-13.650=11.550$ kerupuk per hari \\
produksi perhari & 11.550 x Rp. 100 = Rp. 1.155 .000 per hari \\
& Rp. 1.155.000 x Margin 40\% $=$ Rp. 462.000,- per hari \\
\hline \multicolumn{1}{|c|}{ Total Economic gains } & Rp. 20.000,- + Rp. 462.000 = Rp. 482.000,- \\
\hline Production Cost (utility \& & 360 Watt x 2,5 jam x Rp 928 per kWh= Rp. 835 per hari \\
maintenance + depresiasi) & Maintenance cost = Rp. 5.000,- per hari \\
& Depresiasi mesin = Rp. 16.025,-- \\
& Total production cost = Rp. 21.860 per hari \\
\hline Return on Invesment & Rp. 5.000.000 / (Rp. 482.000 - Rp. 21.860) \\
& $=11$ hari \\
\hline Kenaikan produktivitas & $80 \%$ \\
\hline
\end{tabular}

\section{KESIMPULAN}

Kesimpulan yang diperoleh dalam penelitian ini adalah dari modifikasi mesin produksi proses pencetakan pada Usaha Kecil Menengah kerupuk, diperoleh peningkatan kapasitas produksi sebesar $80 \%$ perhari, dengan pengurangan waste 2,5\% menjadi hanya 0,2 \% dan peningkatan kesehatan keselamatan kerja.

\section{SARAN}

Penelitian selanjutnya penggantian energi kayu dalam proses steamer, yang desainnya memerlukan biaya yang cukup besar.

\section{DAFTAR PUSTAKA}

[1] http://economy.okezone.com.2011.Hubungan UKM dan ekonomi Indonesia.

[2] Miriam,Borchardt. Marcos, H Wendit. At all. Redesign of a component based on ecodesign practices : environmental impact and cost reduction achievements. Journal of Cleaner Production.19(2011)49-57.Elsevier.2010.

[3] M, Despeisse. PD Ball.at all. Industrial ecology at factory level-a conceptual model.Journal of Cleaner Production 31 (2012) 30-39. Elsevier.2012. 
[4] Ru-jen Lin.Chwen Sheu.Why Do Firms Adopt/Implement Green Practices?-An Institutional Theory Perspective.Procedia-Social and Behavioral Sciences 57 (2012) 533540.Elsevier.2012

[5] Tom Tuttle, John Heap.(2007). Green productivity: moving the agenda. Vol. 57 Iss: 1, pp.93 - 106. International Journal of Productivity and Performance Management. 